\title{
Qualität durch multiprofessionelles Leistungsspektrum
}

\author{
Seit 1. April 2021 führen die Grazer Elisabethinen zwei \\ Standorte mit einem multiprofessionellen Schwerpunkt \\ in der Altersmedizin.
}

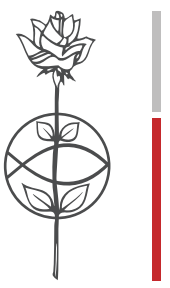

\section{die elisabethinen}

gesundheit \& leben

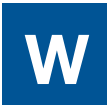
ir helfen, wo die Not der Zeit es erfordert." Dieses Wort aus der Charta der Elisabethinen in Österreich ist eine Kompassnadel für die Organisationsentwicklung des Grazer Krankenhauses der Elisabethinen mit seinen beiden Standorten. Die Altersmedizin ist dabei ein wesentlicher Teil im Leistungsspektrum des gemeinnützigen Akutspitals.

Die Abteilung für Neurologie und die Abteilung für Psychiatrie und Psychotherapie, die mit dem Versorgungsauftrag für die Alterspsychiatrie verbunden ist, der schrittweise umgesetzt wird, am Standort in Eggenberg sowie die Abteilung für Innere Medizin am Standort in der Elisabethinergasse fördern ein multiprofessionelles Panorama für ein gelingendes Leben im Alter. Besondere Schwerpunkte der Abteilung für Innere Medizin sind in diesem Zusammenhang die Station für Akutgeriatrie und Remobilisation sowie der Bereich Palliativ und Hospiz.

Die Palliativ- und Hospizbetreuung sowie das Bemühen um eine humane Ethik zumal am Lebensende sind ein Herzensanliegen des Ordens und seiner rund 700 Mitarbeiterinnen und Mitarbeiter. Der Bereich umfasst die Palliativstation und das stationäre Hospiz St. Elisabeth sowie das VinziDorf-Hospiz für Obdachlose. In den beiden Hospizen werden Menschen mit einer unheilbaren Erkrankung an ihrem Lebensende betreut.

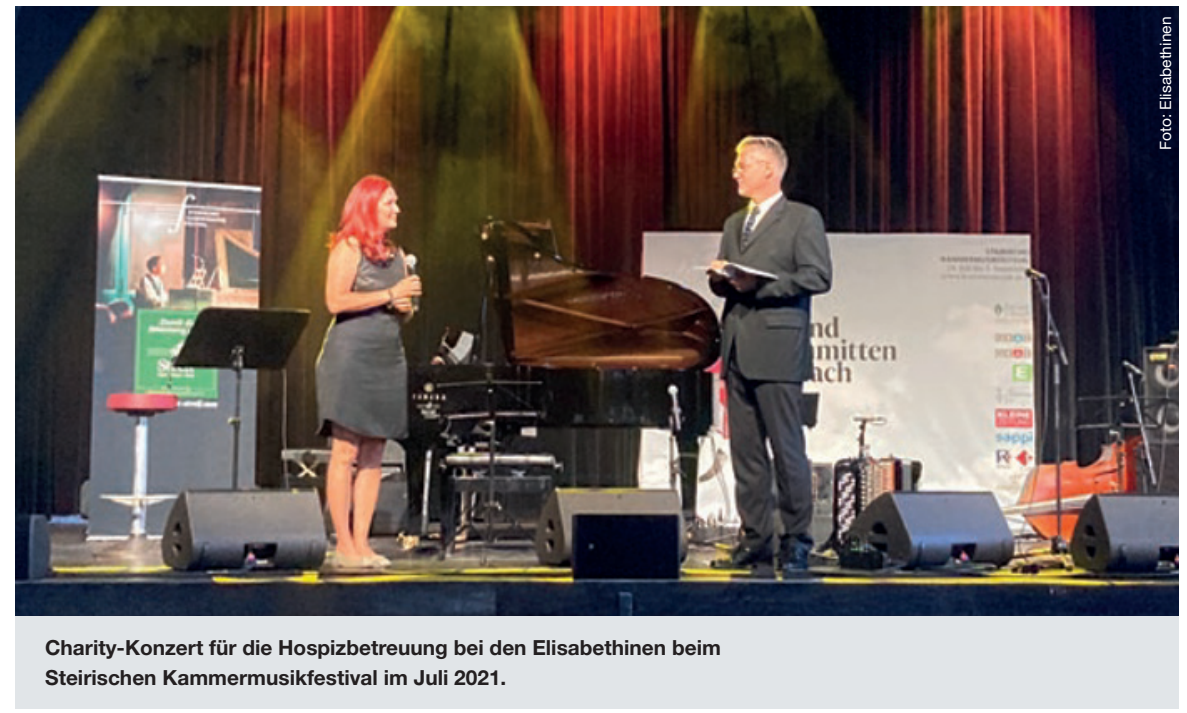

Ein Teil der Hospizbetten steht wohnungslosen bzw. nicht versicherten Menschen am Rand der Gesellschaft zur Verfügung. In den insgesamt 4 Hospizbetten werden die Bewohnerinnen und Bewohner bei den Elisabethinen 24 Stunden täglich mit Empathie und Kompetenz betreut. 2020 starteten die Elisabethinen einen digitalen „Patenkalender" (https://paten.elisabethinen.at). Dabei kann man Patenschaften übernehmen und dadurch Bewohnern helfen, für welche die tägliche Eigenleistung sonst nicht leistbar wäre. Auch Sachspenden und ehrenamtliche Mitarbeit sind möglich und willkommen. Die Elisabethinen machen auch mit Veranstaltungen auf die Möglichkeit zur Unterstützung der Hospizbetreuung aufmerksam.
Eine umfassende Palliativ- und Hospizbetreuung ist heute umso bedeutsamer, da die Würde des menschlichen Lebens in allen seinen Dimensionen durch die aktuelle gesellschaftspolitische Diskussion rund um dem „assistierten Suizid“ besonders herausgefordert ist. Im Leitbild des Krankenhauses der Grazer Elisabethinen (2018) heißt es dazu klar: „Es ist Teil unseres irdischen Lebens, dass es zu Ende geht - aber wir wirken nicht aktiv daran mit."

Kontakt:

Mag. Peter Rosegger, MBA

Leiter Wirkfeld „Iernen\&leben“ und Öffentlichkeitsarbeit

Krankenhaus der Elisabethinen Graz peter.rosegger@elisabethinen.at 